\title{
The economic impact of sight loss and blindness in the UK adult population
}

\author{
Lynne Pezzullo ${ }^{1}$, Jared Streatfeild ${ }^{1 *}$ (D) Philippa Simkiss ${ }^{2}$ and Darren Shickle ${ }^{3}$
}

\begin{abstract}
Background: To quantify the economic impact of sight loss and blindness in the United Kingdom (UK) population, including direct and indirect costs, and its burden on health.

Methods: Prevalence data on sight loss and blindness by condition, Census demographic data, data on indirect costs, and healthcare cost databases were used. Blindness was defined as best corrected visual acuity (BCVA) of $<6 / 60$, and sight loss as BCVA $<6 / 12$ to $6 / 60$, in the better-seeing eye.

Results: Sight loss and blindness from age-related macular degeneration (AMD), cataract, diabetic retinopathy, glaucoma and under-corrected refractive error are estimated to affect 1.93 (1.58 to 2.31) million people in the UK. Direct health care system costs were $£ 3.0$ billion, with inpatient and day care costs comprising $£ 735$ million (24.6\%) and outpatient costs comprising $£ 771$ million (25.8\%). Indirect costs amounted to $£ 5.65$ (5.12 to 6.22) billion. The value of the loss of healthy life associated with sight loss and blindness was estimated to be $£ 19.5$ (15.9 to 23.3) billion or $£ 7.2$ (5.9 to 8.6) billion, depending on the set of disability weights used. For comparison with other published results using 2004 disability weights and the 2008 estimates, the total economic cost of sight loss and blindness was estimated to be $£ 28.1$ (24.0 to 32.5) billion in 2013. Using 2010 disability weights, the estimated economic cost of sight loss and blindness was estimated to be $£ 15.8$ (13.5 to 18.3) billion in 2013.
\end{abstract}

Conclusions: The large prevalence of sight loss and blindness in the UK population imposes significant costs on public funds, private expenditure, and health. Prevalence estimates relied on dated epidemiological studies and may not capture recent advances in treatment, highlighting the need for population-based studies that track the prevalence of sight-impairing eye conditions and treatment effects over time.

Keywords: Sight loss, Blindness, Visual impairment, Cost-of-illness, Health economics, Cost analysis, United Kingdom

\section{Background}

Sight loss and blindness cause a considerable amount of health burden globally. In the UK, the burden due to sight loss and blindness has increased from around 143,600 to more than 154,600 disability adjusted life years, while the total disability adjusted life years due to all causes in the UK have been decreasing [1]. Demographic ageing is leading to a substantial increase in the prevalence of age-related sight-impairing conditions, and associated increases in their costs [2]. However, a significant proportion of sight loss and blindness is preventable, suggesting that more investment in prevention and early intervention could improve socioeconomic outcomes in the UK [3].

\footnotetext{
* Correspondence: jstreatfeild@deloitte.com.au

'Deloitte Access Economics Pty Ltd, 8 Brindabella Circuit, Canberra Airport 2609, ACT, Australia

Full list of author information is available at the end of the article
}

Estimating the cost of sight loss and blindness is essential if their socioeconomic impact is to be fully understood and if the cost effectiveness of prevention and treatment is to be calculated. Calculation of the economic cost in the UK is necessary as an input to assist decision makers to evaluate policy and to prioritise health expenditure, including research expenditure. Moreover, it is necessary to understand how certain costs are changing over time, and whether any progress has been made against key objectives, including eliminating preventable sight loss and blindness through effective interventions such as screening and early intervention with treatments.

To date, there has been little work estimating the economic impact of sight loss and blindness specifically in the UK context [2], although a study for the Royal 
National Institute of Blind People exists that estimates the prevalence and cost of sight loss and blindness in 2008 [4]. Previous peer-reviewed studies have aimed to identify the unit costs of sight loss and blindness for use in cost-effectiveness analysis [5], with limited focus placed on estimating the overall impact.

Internationally, a substantial body of literature exists that estimates various costs associated with sight loss and blindness, including direct medical costs, indirect costs and intangible costs. A recent paper summarised 22 cost of illness and intervention studies, including one study in the UK, finding that the mean annual expenses per person for sight loss and blindness range from US $\$ 12175$ to US $\$ 24180$ depending on severity [6]. However, very few cost of illness studies related to sight loss or blindness have been published in peer-reviewed literature, and none have been published within the UK context. In Canada, the socioeconomic impact of sight loss and blindness was estimated to be $£ 26,587$ per person with sight loss or blindness [7]. In Japan, the cost was estimated to be $£ 28,672$ per person with sight loss or blindness [8]. Both values were converted using purchasing power parity in 2007.

This research has calculated the prevalence and cost of sight loss and blindness specifically for the UK context in 2013, to provide more current estimates of the various cost components and to compare the changes over the five years since the original Access Economics study was conducted for the UK. This research enables unique comparisons of the socioeconomic impact of sight loss and blindness across countries by using a methodology consistent with work previously conducted in Canada, Australia, Japan and the US. Moreover, this research provides useful analysis of the changing cost of sight loss and blindness within the UK. As such, this research will help inform decision-making with regards to policy and commissioning of effective interventions for prevention, detection, treatment and care of sight loss and blindness and to provide direction for future research.

\section{Methods}

The costing methodology used in this study is based on a prevalence approach to cost measurement [9]. Prevalence approaches measure the number of people with a given condition in a base period and the costs associated with treating them, as well as other financial and nonfinancial costs in that year due to the condition. This approach is combined with both top-down and bottom-up approaches to estimate expenditure for each condition. [9]. To identify materials of relevance to this study, a literature review was conducted for each cost component, noting this review was targeted rather than systematic since the former was considered more fit-for-purpose given this was a cost of illness study where many of the inputs are in data sets and grey literature (e.g. government documents) not in peer-reviewed literature.

\section{Prevalence}

To determine prevalence, sight loss and blindness for this research are defined as:

- blindness (severe sight loss) is defined as best corrected visual acuity (BCVA) of $<6 / 60$ in the better-seeing eye; and

- sight loss is defined as BCVA of $<6 / 12$ to $6 / 60$ in the better-seeing eye.

A number of data sources, both local and international, were utilised to estimate the prevalence of sight loss and blindness by age, gender, ethnicity, severity and major cause (Additional file 1). Prevalence rates were adjusted for comorbidity using relativities of each condition to total sight loss and blindness. Total sight loss and blindness data by cause were derived by five year age groups. Within age groups, the relativities between the visual acuity groupings were used to separate total prevalence. For example, for those aged 75 and above the Medical Research Council (MRC) trial of assessment and management of older people in the community was used to establish overall prevalence [10], including the relativities between BCVA $<6 / 18,6 / 18-6 / 30$, and $<6 / 60$ - the visual acuity groupings reported in the study. [11] The relativities of each condition were then applied to the total prevalence to adjust for comorbidities [11-14]. The prevalence rates for the other age groups were derived in a similar way. Ethnicity splits [15-22], calculated based on relative risks for specific eye disease type, were applied to the prevalence rates by age. Where these were not available, prevalence rates were assumed to be the same as for the general population (i.e. no difference by ethnicity group). Detailed tables and methodology outlining the prevalence rate estimates by age, gender and condition are available in the supplementary file (Additional file 1).

These derived prevalence rates were applied to population estimates by age, gender, ethnicity and region from the 2011 UK Census and sub-national population projections for government office regions developed by the Office for National Statistics (ONS). [23, 24] Greater London Authority projections of the London population by ethnicity, gender and five-year age group between 2013 and 2041 were utilised to project ethnicity groups to 2051 across the entire UK population as they were the only publicly available projections that provided age and gender breakdowns for ethnic groups [25]. Average annual growth rates between 2013 and 2041, calculated for each ethnicity group and by five-year age groups, were assumed to apply for the period between 2041 and 
2051. The total projected population, by each age and gender group were adjusted to coincide with ONS population projections [26], with each ethnicity group maintaining the same relative share of the total population.

\section{Health care system expenditure- direct costs}

Direct health system costs were determined using a combination of a top down and bottom up approach. [9] The top down approach is based on Reference Cost data collected by the Department of Health in England [27]. Health care services within the Reference Cost data are broken down into Healthcare Resource Groups (HRGV.4+) and contain 58 HRG codes that specifically related to eye disease. To determine hospital inpatient expenditure, each HRG code was mapped to each condition. Alternative sources such as Scotland's Health Service Costs [28], Wales' Health Statistics Wales [29], and Northern Ireland's Reference Costs [30] were used for other devolved nations. Non-admitted expenditure was also estimated using these data. Non-admitted expenditure consists of outpatient costs and other community services, including paramedic services, consultant led outpatient attendances and non-consultant led outpatient attendances.

Other health system expenditure was constructed using a 'bottom up' approach [9]. This includes costs associated with sight loss and blindness from prescribing expenditure, general ophthalmic services, injurious falls, research and development (R\&D), residential and community care, and capital and administration.

Expenditure data associated with prescriptions such as ranibizumab (Lucentis), aflibercept (Eylea), anti-infective eye preparations, corticosteroids, mydriatics, cycloplegics, local anaesthetics and other ophthalmic preparations was sourced from each devolved nation's statistical reports as appropriate using national formulary classifications to ensure the prescription is related to sight loss or blindness [31-34]. For example, in England this is the British National Formulary [31].

Similarly, data on general ophthalmic services [35-38], residential and community care attributable to sight loss or blindness [28, 39-41], and capital and administration attributable to sight loss or blindness [29, 42-44] were also sourced from each devolved nation's statistical reports as appropriate. Residential and community care data sources indicate the number of recipients with sight loss or blindness. To estimate the total cost of residential and community care services, average unit costs for residential and community care - derived by dividing total expenditure by total services - were applied to each residential and community care service. To attribute capital and administration costs to sight loss and blindness, it was assumed that total capital and administration expenses are incurred at the same rate as the overall health expenditure in England, of which $2.0 \%$ is for sight loss and blindness [45].

The government sources outlined do not provide sufficient information to estimate the private health care expenditure associate with sight loss. As the public versus private health care expenditure split for health services has been relatively stable over the past two decades with public spending only rising $3 \%$ of the total expenditure by 2015 [46], private health care expenditure was derived using data from Williams et al. (2000) [47]. Expenditure associated with injurious falls due to sight loss and blindness was derived using hospital episode statistics [48] and a model developed by Scuffham et al. (2002) [49].

R\&D expenditure attributable to sight loss and blindness was estimated by applying the share of eye and ear health $R \& D$ [50] to total health related R\&D investment from private industry, non-profit organisations and public funds through the government [51]. To separate eye and ear health $R \& D$, expenditure for eye related $R \& D$ was assumed to maintain the same proportion as the estimated disease burden attributable to ear and eye health from the World Health Organization (WHO) Global Burden of Disease project for high income countries [52]. This measure was also validated against the most recent Global Burden of Disease project for the UK, which showed that the measure was not sensitive to changes over time with the measure being $29.1 \%$ using the more recent approach rather than $29.8 \%$ using the earlier approach for high income countries $[1,52]$.

\section{Indirect costs:}

There are two types of indirect costs of sight loss and blindness: the financial costs associated with lower productivity from premature mortality, lower workforce participation and absenteeism, and the cost of informal carers, aids and modifications and deadweight losses; and the non-financial costs from loss of healthy life, that are analysed in terms of disability adjusted life years (DALYs).

In evaluating indirect costs, it is important to make the economic distinction between real costs and transfer payments. Rather than payments made for the use of any good or service, transfer payments are a transfer of claims over real resources. Transfer costs are important to estimate in order to attribute who bears the costs of sight loss and blindness, and to calculate the deadweight loss to society.

A human capital approach is adopted to estimate productivity losses $[9,53]$. Employment rates are lower for people with sight loss relative to the average person in the UK (after age standardisation) [54]. It is assumed that, in the absence of sight loss, people with sight loss would participate in the labour force and obtain 
employment at the same rate as other people in the UK and earn the same average weekly earnings.

To estimate premature mortality rates from sight loss and blindness in 2013, the country specific mortality rate [55-57] was multiplied by an odds ratio of 2.34, which was derived from the Melbourne Visual Impairment Project (MVIP) [58]. Deaths due to sight loss and blindness by age and gender were calculated from the demographic data and mortality rates utilising the attributable fraction approach.

The productivity loss from those who die prematurely was estimated based on the assumption that if they had lived, the person would have earned an average annual income up until their retirement. Average gross annual incomes were calculated as $£ 29,297$ for males and $£ 23,946$ for females in England, $£ 26,702$ for males and $£ 21,939$ for females in Wales, $£ 28,304$ for males and $£ 23,608$ for females in Scotland, and $£ 24,825$ for males and $£ 22,958$ for females in Northern Ireland [59]. No on-costs have been included in calculating productivity losses.

Retirement age was represented by the State Pension age. The eligibility age for the State Pension is increasing in the UK over the next decade. For the purposes of estimating the productivity loss associated with premature mortality, this was set at the 2013 eligibility age, which was 65 for males and 62 for females. Average life expectancy was assumed to be 79 for males and 83 years for females. For the age brackets $75-84$ and $85+$ for both males and females, life expectancy was assumed to be 85 years and 90 years respectively [60].

The number of people who were in employment at the time of their death was calculated by multiplying the number of deaths due to sight loss or blindness by the employment rate of those with 'difficulty seeing', which on average was 55.5\% [54]. The present value of lost earnings (gross) was calculated using a discount rate of $3.5 \%$ over the number of years until retirement with sensitivity analysis at $1.5 \%$, as recommended by the National Institute for Health and Care Excellence [61].

In addition to workforce separation, people with sight loss or blindness may be absent from work more often due to their condition. Access Economics (2006) [62] estimated that people with sight loss or blindness in the United States were likely to have an additional 4.1 days off work per year on average $[7,8]$. Productivity costs from increased absenteeism were calculated as the average number of days absent per year due to sight loss or blindness adjusted for employment $[7,8]$.

Total informal care costs were calculated based on a top-down approach using the 2011 Census data to determine the number of informal care hours provided to people with sight loss, adjusted for population growth to 2013. An opportunity cost methodology [62-64] was used to value these hours, which measures the value in alternative use of time spent caring. This is valued by productivity losses (or value of leisure time) associated with caring.

The total number of hours of informal care were calculated with the same methodology used by the University of Leeds in valuing informal carers for Carers UK [65]. The cost of informal care related to sight loss and blindness was estimated as the total number of informal care hours multiplied by the average per hour wage rate for males and females, derived from the average annual incomes [59].

The total annual cost of devices and modifications was derived from data from a study conducted by Lafuma et al. (2006) [66] in 2004. Prices were converted into Sterling by applying the exchange rate used within their study $(£ 1=€ 1.5)$ and adjusted to 2013 prices using an average UK inflation rate over that period of $2.71 \%$ [67].

Real costs use up resources, or reduce the economy's overall capacity to produce goods and services. In contrast, transfer payments involve payments from one economic agent to another and include taxation revenue or social welfare payments, which impose deadweight losses on society. Deadweight losses associated with sight loss and blindness include the cost of raising additional revenue to fund public health care system costs, residential and community care, aids and equipment, and direct payments to those with sight loss and blindness and their carers.

While the costs associated with deadweight loss depend on the method used to raise additional taxes, the social cost is not zero and has therefore been included as a cost of sight loss and blindness. This study assumes that additional taxes are raised through income tax rate changes. The average marginal cost of raising additional tax revenue was calculated as 1.12 [68], so for every additional $£ 1$ raised by the UK government to fund costs associated with sight loss and blindness, there is an estimated $£ 0.12$ of deadweight loss. Direct payments from the government to those with sight loss were sourced from the Department for Work and Pensions [69] and the Department of Social Development [70] for Northern Ireland.

\section{Burden of disease}

The overall impact on wellbeing from disability and premature death can be measured as "burden of disease", measured in DALYs. DALYs have two components - the years of healthy life lost due to disability (YLD) and the years of life lost due to premature death (YLL).

The method to quantify the reduction in the stock of health capital is the global burden of disease methodology developed by the WHO [71]. 
In any year, the disability weight of a disease (for example, 0.43 for blindness) reflects a relative health state. This example represents losing $43 \%$ of a year of healthy life because of blindness. The loss of wellbeing for sight loss was estimated using disability weights as per the global burden of disease study from 2004 and 2010, noting the existing debates surrounding the methodologies used to generate each set of disability weights [72-76]. Both sets of disability weights are validated measures and undergo considerable peer review at the time of publication. Presenting the loss of wellbeing using both sets of disability weights has added benefits of enabling comparison with not only the earlier Access Economics study, but also new studies going forward that are based on the 2010 disability weights. Each set of disability weights was applied to prevalence data to calculate DALYs.

The method to value a reduction in the stock of health capital has been based on Mason et al. (2008) [77] using estimates of the value of a statistical life (VSL) derived from the UK Department of Transport. The UK Department of Transport estimated the VSL to be $£ 1.43$ million in 2005 prices. Mason et al. estimated, the value of a year of perfect health to be $£ 70,896$ (in 2005 prices), by applying a discount rate of $1.5 \%$. This is the rate of pure time preference and differs from the standard 3.5\% discount rate as the VSL has been shown to grow at a similar rate as the marginal utility of consumption (approximately $2 \%$ ), and should therefore be excluded [77]. This estimate for the value of a DALY was adjusted to 2013 prices using UK consumer price index to give $£ 88,825$.

\section{Results}

\section{Prevalence}

In 2013, there were an estimated 1.93 (1.58 to 2.31) million people with sight loss and blindness in the UK as a whole, or $3.0 \%$ (2.5\% to $3.6 \%)$ of the population. This includes 255,000 (208,100 to 304,800$)$, or $13.2 \%$ who are blind. The ethnic groups with highest prevalence were white people (3.3\%, range $2.7 \%$ to $3.9 \%$ ), followed by Asians (1.5\%, range $1.2 \%$ to $1.8 \%$ ). The prevalence of sight loss and blindness in the UK was estimated to have increased by 135,115 (7.5\%) since 2008 .

The prevalence of sight loss and blindness is projected to increase with demographic ageing, and in a policy neutral environment, from $3.0 \%$ (2.5\% to $3.6 \%)$ today to $5.4 \%(4.4 \%$ to $6.5 \%)$ or approximately 4 million people by 2050 . In terms of ethnic shares relative to the total population with sight loss and blindness, the share of white people with sight loss and blindness is projected to fall (from $94.9 \%$ to $88.5 \%$ ), while the share of black people is projected to increase from $1.0 \%$ to $1.8 \%$, Asians from $3.0 \%$ to $6.4 \%$, and other ethnicities from $1.1 \%$ to $3.3 \%$.
From 2013 to 2050, the share of sight loss and blindness from AMD is projected to change from $23.1 \%$ to $29.7 \%$, more than doubling from 445,809 (363,900 to 532,800 ) people to 1.23 (1.01 to 1.47 ) million people. The share contributed from cataract is projected to change from $18.7 \%$ to $21.4 \%$, diabetic retinopathy from $4.7 \%$ to $3.1 \%$, glaucoma from $7.2 \%$ to $7.0 \%$, undercorrected refractive error from $38.9 \%$ to $31.3 \%$ while other eye diseases remains constant in its share of total prevalence (rising in absolute terms only).

\section{Health system costs- direct costs}

Direct health care system costs are estimated to amount to $£ 2.99$ billion in UK in 2013. Around 50\% of total direct health care system costs are attributable to hospital recurrent expenditure and non-admitted expenditure, totalling around $£ 1.5$ billion. Further significant cost items include general ophthalmic services ( $£ 614.6 \mathrm{mil}-$ lion or $21 \%$ ), prescribing expenditure ( $£ 380.9$ million or $13 \%)$, and residential and community care services ( $£ 276.8$ million or $9 \%$ ). Other costs include costs due to injurious falls, an attributable portion of capital and administration costs and research and development relating to sight loss and blindness (Table 1).

AMD accounted for $34 \%$ of total health system costs that could be attributed to each of the five conditions (this total excludes residential care and community care services, expenditure associated with injurious falls and capital and administration expenditure). This represents the rapid growth in costs associated with the new anti-vascular endothelial growth factor (VEGF) therapies such as ranibizumab (Lucentis) and Aflibercept (Eylea). Under-corrected refractive error, cataract, diabetic retinopathy, glaucoma and other eye diseases accounted for $21 \%, 20 \%, 10 \%, 7 \%$ and $8 \%$ of total health system costs, respectively.

\section{Indirect costs}

The total of indirect costs attributable to sight loss and blindness in the UK were estimated to be $£ 5654$ (5117 to 6224) million in 2013. Indirect costs for each country are shown in Table 2.

Lower employment participation for those with sight loss and blindness resulted in 90,108 (73,500 to 107,700$)$ fewer people in the UK workforce in 2013 and an estimated loss of $£ 2.43$ (1.98 to 2.90) billion in income (44\% of indirect costs).

The second largest indirect cost component is attributable to informal care, estimated to be around $£ 2.36$ billion (or 43\%) in 2013. Other indirect costs associated with sight loss and blindness in 2013 include expenditure on devices and modifications ( $₫ 409.6$ million or $7 \%$, range 334.3 to 489.6 million), deadweight loss (£379.0 million or $7 \%$, range 378.5 to 379.4 million), 


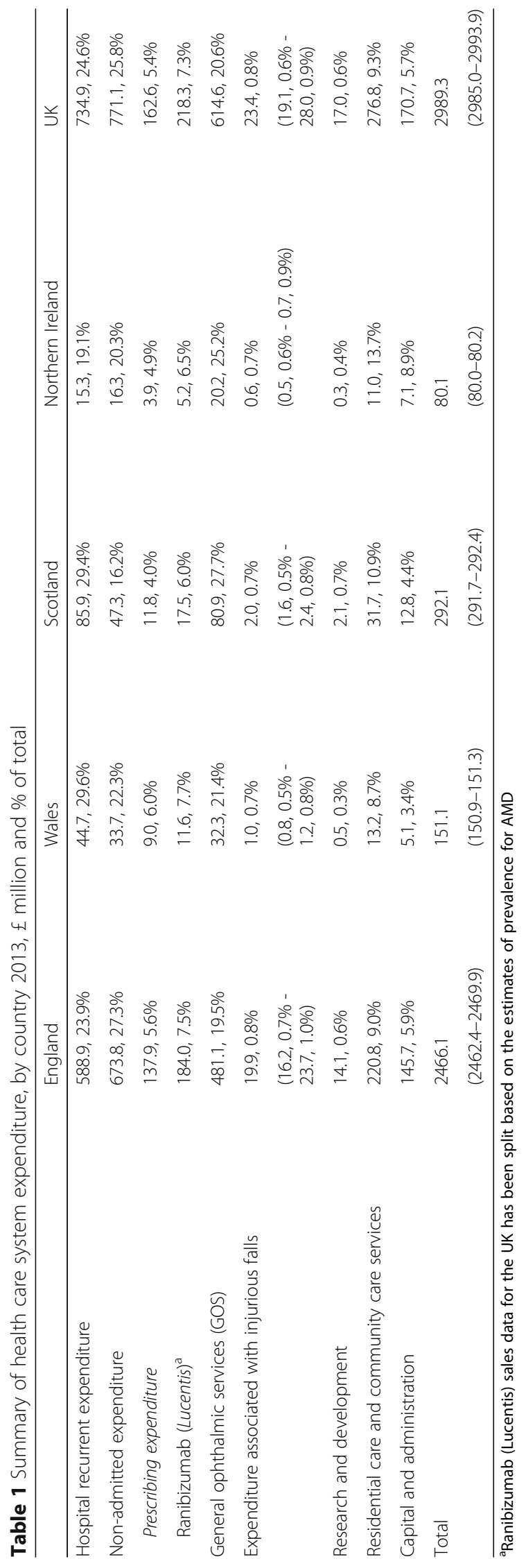


Table 2 Summary of indirect costs 2013 (£ million)

\begin{tabular}{|c|c|c|c|c|c|}
\hline & England & Wales & Scotland & Northern Ireland & UK \\
\hline \multirow[t]{2}{*}{ Lower employment } & 2078.5 & 88.0 & 210.9 & 50.0 & 2427.4 \\
\hline & $(1696.5-2484.2)$ & $(71.8-105.2)$ & $(172.2-252.1)$ & $(40.8-59.8)$ & (1981.2-2901.3) \\
\hline \multirow[t]{2}{*}{ Absenteeism } & 65.6 & 3.7 & 6.5 & 1.9 & 77.6 \\
\hline & $(53.5-78.4)$ & $(3.0-4.4)$ & $(5.3-7.8)$ & $(1.6-2.3)$ & $(63.4-92.8)$ \\
\hline \multirow[t]{2}{*}{ Premature mortality } & 1.77 & 0.09 & 0.23 & 0.05 & 2.14 \\
\hline & $(1.44-2.11)$ & $(0.08-0.11)$ & $(0.19-0.27)$ & $(0.04-0.07)$ & $(1.75-2.56)$ \\
\hline \multirow[t]{2}{*}{ Informal care costs } & 1951.9 & 134.8 & 194.8 & 76.7 & 2358.2 \\
\hline & (1951.9-1951.9) & $(134.8-134.8)$ & (194.8-194.8) & $(76.7-76.7)$ & $(2358.2-2358.2)$ \\
\hline \multirow[t]{2}{*}{ Devices and modifications } & 343.8 & 21.5 & 34.1 & 10.2 & 409.6 \\
\hline & $(280.6-411)$ & $(17.6-25.7)$ & $(27.8-40.8)$ & $(8.3-12.2)$ & $(334.3-489.6)$ \\
\hline \multirow[t]{2}{*}{ Deadweight loss } & 311.8 & 19.8 & 37.0 & 10.3 & 379.0 \\
\hline & (311.4-312.2) & $(19.8-19.8)$ & $(37-37.1)$ & $(10.3-10.3)$ & $(378.5-379.4)$ \\
\hline \multirow[t]{2}{*}{ Total } & 4753.3 & 267.8 & 483.6 & 149.2 & 5653.9 \\
\hline & (4295.4-5239.8) & $(247.0-290.0)$ & $(437.3-532.8)$ & $(137.7-161.3)$ & (5117.4-6223.9) \\
\hline
\end{tabular}

absenteeism and premature mortality (together, $1 \%$ of indirect costs). In the working age population, an estimated 25 (20 to 30) deaths were attributable to sight loss and blindness in 2013, of which 14 (11 to 17) would have been employed.

\section{Burden of disease}

Using disability weights from the 2004 global burden of disease project for comparison with the 2008 estimates and older international studies, the YLDs lost due to sight loss and blindness were estimated as 205,372 $(167,600$ to 245,500$)$ DALYs in the UK in 2013. Based on the number and age-gender profile of deaths, the YLLs from sight loss and blindness were estimated to be $13,734(11,200$ to 16,400$)$, bringing the total to 219,106
$(178,800$ to 261,900$)$ DALYs. The proportion of DALYs attributable to each condition are shown in Fig. 1.

Total DALYs were multiplied by $£ 88,825$ (the value of a DALY) to provide an estimate of $£ 19.5$ (15.9 to 23.3) billion for the total cost associated with the loss of wellbeing. The cost was estimated to be $£ 16.3$ (13.3 to 19.5 ) billion in England, $£ 1.0$ (0.8 to 1.2$)$ billion in Wales, $£ 1.6$ (1.3 to 1.9) billion in Scotland and $£ 0.5$ (0.4 to 0.6$)$ billion in Northern Ireland.

Applying the alternative 2010 global burden of disease disability weights - for comparison with newly published cost of illness studies that adopt these weights - would result in a substantially lower estimate of $81,033(66,100$ to 96,900$)$ DALYs from sight loss and blindness, with the value of the loss of wellbeing estimated to be $£ 7.2$ (5.9 to 8.6) billion in the UK in 2013.

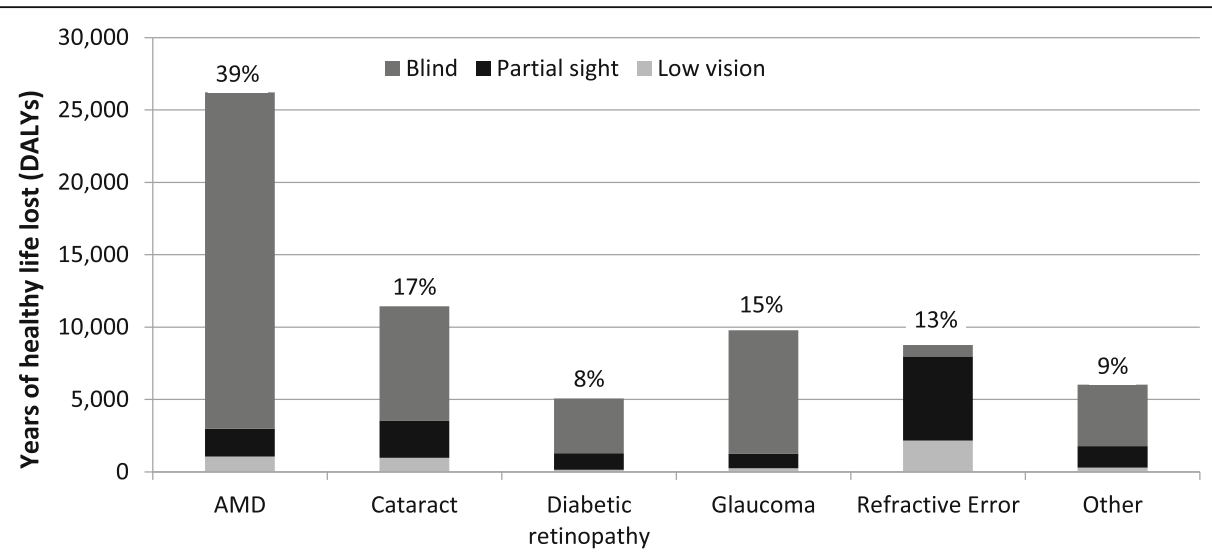

Fig. 1 Burden of disease across conditions in the UK, by severity of sight loss, 2013.

Note: \% refers to the total burden of disease caused by the condition. Burden of disease has been determined using 2004 disability weights. Abbreviations: AMD, age-related macular degeneration; DALYs, disability-adjusted life years 


\section{Discussion}

The results of the study indicate that sight loss and blindness in the adult population places a large economic cost on the UK, estimated to total $£ 28.1$ (24.0 to 32.5) billion in 2013 using 2004 disability weights, or $£ 15.8$ (13.5 to 18.3 ) billion using 2010 disability weights. The former estimate provides useful comparison with 2008 estimates and work undertaken in Canada and Japan, which use similar disability weights. The per capita cost of sight loss and blindness was estimated to be $£ 14,549$, which is lower than both Canada and Japan which were $£ 26,587$ and $£ 28,672$ respectively when converted using purchasing power parity in 2007 [7, 8].

Comparing 2008 and 2013, the cost of sight loss and blindness in the UK is estimated to have increased by $27.8 \%$. The increase is driven by higher prevalence as well as an estimated 39\% increase in health system expenditures, including a more than doubling of prescribing expenditures due to the inclusion of the cost of ranibizumab (Lucentis) and over a 50\% increase in nonadmitted expenditures. However, residential and community care costs associated with sight loss and blindness have fallen over the period as the rate of accessing these services for people with sight loss or blindness has fallen relative to 2008. People with sight loss and blindness have been disproportionately affected, with the rate of accessing services declining by more than for other disability groups [78]. This may be both a result of a decline in the number of people with sight loss or blindness that have a Certificate of Vision Impairment and a result of cuts to social care budgets in the UK from 2010 onwards. Recently, more funding has been committed to increasing social care services and other forms of assistance. For example, the Care Act in England which came into effect in April 2015 legislates that Local Authorities must provide minor aids and adaptations up to the value of $£ 1000$ for the purpose of assisting with nursing at home or aiding daily living, which would have implications for expenditure in the future.

The estimated $49 \%$ rise in productivity losses was due to a fall in the employment rate for people with sight loss and blindness, thereby widening the employment gap compared to the general population. This also directly contributed to the fall in the cost associated with absenteeism which is dependent on the number of employed people with sight loss and blindness.

With population ageing, the prevalence of AMD is estimated to have risen nearly $49 \%$ over the period 2008 to 2013. The ageing population and increasing prevalence of diabetes in UK is associated with estimated prevalence increases of over $40 \%$ for cataract, glaucoma and diabetic retinopathy. However, the prevalence of sight loss and blindness due to under-corrected refractive error has decreased over the same period, possibly due to more people accessing corrective services as the value of vouchers for accessing corrective glasses and the number of eye tests has increased.

Importantly, the burden of disease from sight loss and blindness is estimated to have increased by more than $25 \%$ compared with 2008, indicating that the substantial burden of disease from sight loss and blindness is still growing in the UK.

While unavoidable, age-related conditions contribute greatly towards the growing economic costs and burden of sight loss and blindness in the UK; although, a substantial proportion of this is still preventable. For example, it has been estimated that the majority of visual impairment worldwide, including blindness, may be preventable using cost-effective treatment methods that are already available. Further, WHO Member States (including the UK) have committed to reducing the prevalence of avoidable visual impairment by $25 \%$ by 2019 compared to the baseline established by the WHO in 2010 [3].

To align with data sources, the definitions of sight loss and blindness in this research differ slightly from the guidelines for certifiable severely sight impaired (blindness) and sight impaired (partial sight), which are [79]:

- severely sight impaired is defined as BCVA of $<3 / 60$, or those $>3 / 60$ and $<6 / 60$, and $<6 / 60$ with the presence of contracted field of vision; and

- sight impaired is defined as BCVA of $>3 / 60$ and $<6 / 60$ with full field, or $>6 / 60$ and $<6 / 24$ with moderate contraction of the field, or $<6 / 18$ or even better with marked contraction of visual field.

This means that the prevalence numbers reported here will not align with certifiable sight loss and blindness. While the scope of the exercise was not to report on certifiable sight loss and blindness, it is important to recognise that the economic costs and burden of sight loss and blindness reported in this article are larger than for certifiable sight loss and blindness alone. This distinction is important for policy implications.

There are some limitations to this study. The methods for this study outlined the use of grey literature and a non-systematic search strategy, noting that this was fit-for-purpose. The estimates presented in this article should be interpreted with this in mind. Judgement and experience undertaking cost of illness studies - particularly for sight loss and blindness in the UK [4] and internationally [2, 7, 8, 80] - has been used to ensure that the estimates are as accurate and complete as possible without undermining the quality of the estimates presented. 
With reference to health expenditure costs, using a top-down approach to estimate expenditure has advantages of readily available data, simplicity and low cost to conduct analysis. However, top-down approaches rely on accuracy of data recording. For example, when determining direct health system expenditure in hospitals, the top-down approach utilises healthcare resource groups where expenditure is associated with eye conditions as the primary cause. In contrast, a bottom-up approach that uses anonymised patient records linked to hospital episode statistics can track expenditure for individuals identified as having sight loss or blindness regardless of the primary reason for admission, such as falls. However, linked data is often not readily available for research purposes, and this type of approach often requires costly data analysis. Further, a bottom-up approach can still be subject to data recording issues, including in clinical coding data. When considering primary diagnosis data, clinical coding errors occur in approximately $11 \%$ of cases, and is higher for secondary diagnosis data [81]. This can lead to poor tracking of expenditure attributed to eye health conditions, and limits the application of a bottom up approach. Noting the limitations of a top down approach, the costs presented in this analysis are estimates, although the methods which they are based on are peer-reviewed [80], and have been utilised in other countries previously $[2,7,8,80]$.

In addition, recent healthcare or policy changes may not be captured appropriately. For example, it was assumed that there have been little to no changes in the private expenditure for sight loss or blindness procedures since 1998 [47]. The estimated private expenditure for procedures was approximately $£ 150$ million. If there has been a trend for these procedures to be publically funded as with overall health expenditure [46], there would likely be small downward correction to the total cost of sight loss or blindness in the UK.

To estimate the R\&D expenditure attributable to sight loss and blindness, it was assumed that the proportion of health burden due to sight loss or blindness relative to total eye and ear health burden applied to $R \& D$ expenditure. In reality, this assumption may be overly simplistic for R\&D expenditure, but it does provide a useful starting point. The R\&D expenditure was estimated to be $£ 17.0$ million, which may or may not fully capture the actual research resources devoted to sight loss and blindness in the UK.

For community and social support services provided to people with sight loss or blindness, unit costs were assumed to be the same as for all service recipients. Also, capital and administration expenditure was assumed to be attributed to sight loss and blindness in a similar proportion to overall health expenditure. These are necessary simplifying assumptions due to a lack of available data. For example, it is still important to include the cost of having surgery equipment and infrastructure to provide cataract surgery. Likewise, a person with sight loss or blindness would likely receive an average level of support from community and social support services.

Another potential limitation is using a human capital approach to estimate productivity losses, which can lead to higher estimates of the cost of unemployment due to sight loss and blindness than alternative approaches such as the friction cost approach $[9,53]$. The human capital approach differs to the friction cost approach in that the productivity loss of the worker's contribution relative to the absence of the condition is included for the duration of the condition, whereas the friction cost approach only includes productivity losses until the worker is replaced $[9,53]$. The human capital approach is appropriate for industrialised countries in which there is near full employment as the removal of labour constrains economic growth in the long run production possibilities frontier, ceteris paribus $[53,80]$. If the friction cost approach was used, the estimated productivity loss of $£ 2.43$ billion would be expected to be considerably smaller.

To estimate the costs of informal care provision, average wages were used. This may be seen to overstate the cost of informal care associated with sight loss and blindness. However, it is important that informal care is valued at average wage rates as this captures the value of lost opportunity of undertaking leisure time, which is proxied using the average age and gender specific wage rate $[82,83]$. Moreover, if informal care was not provided, it is likely that formal care would be used as a substitute where available, which would have a higher replacement cost than the estimates presented in this study.

Regarding absenteeism estimates, the estimated days off work and methods are consistent with the methods used by Roberts et al. (2010) [8] and Cruess et al. (2011) [7], which provides useful comparison of the work impacts of sight loss and blindness between Canada, Japan, the United States and the UK. However, while the methods are consistent, the estimates in all studies are now based on older employment information from the United States, and no estimates specific to the UK are available. Furthermore, no recent studies have been identified that attempt to classify absenteeism impacts [6]. Further research surrounding the effect of sight loss and blindness on work should be undertaken.

To estimate ethnicity groups by age and gender to 2050, this research utilised Greater London Authority projections [25]. A number of other methodologies and sources have attempted to provide ethnicity projections over the long term. Prominent projections for the UK suggest that the ethnic minority share of the population 
would increase from approximately $13 \%$ in 2001 to between 20 and 25\% [84] to $44 \%$ [85] by 2051 and 2056, respectively. This contrasts with minority groups representing approximately $18 \%$ of the total UK population by 2050 estimated in this research. A decision was made to use Greater London Authority projections as data was available by year and did not require linear interpolation between 2001 and 2051. It is noted that there is substantial uncertainty surrounding population and ethnicity group projections. Although ethnic composition does not affect prevalence substantially, sensitivity analysis was nonetheless conducted on prevalence estimates to account for this uncertainty. Confidence intervals from prevalence studies were weighted by sample size to estimate a robust prevalence range. The ranges presented in this research reflect a decrease or increase in prevalence by $18.4 \%$ and $19.5 \%$, respectively.

Finally, quality adjusted life years (QALYs) are typically used in the UK for cost effectiveness analysis [5, 86]. This means that DALYs are unfamiliar to the UK context. DALYs are recommended in the Vancouver group guidelines to measure the burden of disease due to sight loss and blindness, measuring the disability imposed on an individual or the loss of healthy life years [80]. DALYs have been used in a number of studies to estimate the cost burden of sight loss and blindness internationally, and provide a useful basis for comparison across countries. [2, 82, 87] QALYs often rely on preference-based health related quality of life measures elicited from general population samples or from groups of people with the specific condition (e.g. sight loss or blindness), which can make it difficult to make comparisons internationally or with other conditions [88]. DALYs also use a standard life expectancy tables across countries, which make international comparisons easier [88]. For these reasons, DALYs are appropriate and useful in cost of illness studies.

Going forward, more precise and reliable epidemiological information is required to make better estimates of the total national prevalence and costs associated with sight loss and blindness. As the majority of prevalence studies are almost a decade old, the prevalence estimates may not capture those in non-community settings, people with learning disabilities and dementia, or recent advances in treatment. In particular, the effects of recent growth in the use of anti-VEGF therapies to treat AMD and diabetic retinopathy are unlikely to be taken into account in prevalence estimates, although they were in the cost estimates. Anti-VEGF medicines have been shown to both slow and reverse some instances of sight loss and blindness [89].

Changes in eligibility for sight tests funded by the $\mathrm{Na}$ tional Health Service (NHS) may have altered detection rates, which may then have resulted in earlier treatment and a reduction in the prevalence of sight loss and blindness. Specifically, in 2006, NHS Scotland expanded the eligibility criteria for NHS funded eye tests so that the entire Scottish population receives free eye tests. Subsequent adjustments to eligibility in relation to the frequency of free eyes tests were also made. Increased eligibility for comprehensive eye examinations may have benefits from the societal perspective in Scotland if policy encourages a shift in emphasis from the sale of optical appliances to eye health, and if this leads to higher risk individuals receiving eye examinations [90].

These limitations of prevalence data highlight the need for high quality, population-based epidemiological studies to track the prevalence of all eye conditions in the UK and the impacts of treatment over time. Building on the evidence base longitudinally in this manner could also capture changes that are occurring within the population (e.g. in risk factors such as smoking rates), enabling more accurate and timely estimates of the economic costs associated with sight loss and blindness. UK-wide population projections that include ethnicity splits would also be highly beneficial for future studies estimating the economic impact of sight loss and blindness in the UK.

Despite the limitations with recent prevalence data, this study provides an important, and likely accurate picture of the economic costs associated with sight loss and blindness in the UK. To provide some reassurance to the reader that this limitation in prevalence data does not undermine the overall estimates presented in this study, we examined the number of people who are registered as partially sighted or blind (i.e. certifiable sight loss or blindness) with England councils. In 2008, 309,265 people were registered as either partially sighted or blind in England [91]. In 2014, 291,100 people were registered as either partially sighted or blind, a decrease of $6 \%$ [91]. The number of people registering with councils may have declined due to changes in care needs, various policy considerations or an overall decrease in prevalence. However, the magnitude of this change indicates that the expected prevalence in 2013 is within the sensitivity analysis conducted, noting that this is on the lower end of the sensitivity analysis at worst.

Overall, the large prevalence of sight loss and blindness means sight loss in the UK adult population imposes a substantial cost on public funds, private expenditure, and health. This study did not estimate the expected large, and additional costs, associated with sight loss and blindness for children (less than 18 years of age) so the total cost is expected to be underestimated.

Data on the prevalence of childhood sight loss and blindness in the UK is limited and variable. More research needs to be undertaken into measuring childhood sight loss and blindness and the associated economic costs within the UK. 


\section{Conclusion}

Estimating the cost of sight loss and blindness is essential if their socioeconomic impact is to be fully understood. The large prevalence of sight loss and blindness in the UK population imposes significant costs on public funds, private expenditure, and health - estimated to total $£ 28.1$ (24.0 to 32.5 ) billion in 2013 using 2004 disability weights, or $£ 15.8$ (13.5 to 18.3 ) billion using 2010 disability weights. Prevalence estimates relied on dated epidemiological studies and may not capture recent advances in treatment, or the substantial increase in the prevalence of age-related sight-impairing conditions due to demographic ageing, and associated increases in their costs. Importantly, this study takes account of new data to update the understanding of the economic impact of sight loss and blindness in the UK, enabling international comparison and an estimate of the change over the five years between 2008 and 2013. Finally, this study highlights the need for population-based studies that track the prevalence of sight-impairing eye conditions and treatment effects over time.

\section{Additional file}

Additional file 1: The economic impact of sight loss and blindness in the UK adult population - prevalence rates by age, gender, ethnicity and severity. This additional file provides a detailed overview of methods to estimate prevalence, any assumptions and the prevalence data sources underlying this research article. (DOCX $47 \mathrm{~kb}$ )

\section{Abbreviations}

AMD: Age-related macular degeneration; BCVA: Best corrected visual acuity; DALY: Disability adjusted life year; HRG: Healthcare Resource Groups; NHS: National Health Service; ONS: Office for National Statistics; QALY: Quality adjusted life year; R\&D: Research and development; UK: United Kingdom; VEGF: Vascular endothelial growth factor; VSL: Value of a statistical life; WHO: World Health Organization; YLD: Years of healthy life lost due to disability; YLL: Years of life lost due to premature mortality

\section{Acknowledgements}

Not applicable.

\section{Funding}

This research was supported by the Royal National Institute of Blind People and Novartis Pharmaceuticals UK Ltd. RNIB engaged LP and JS to design the study and undertake the analysis. Novartis Pharmaceuticals UK Ltd. provided an educational grant to RNIB for this purpose. Novartis Pharmaceuticals UK Ltd. had no role in the analysis, interpretation or preparation of the manuscript.

\section{Availability of data and materials}

The data sets supporting the results of this article are available to the public from various government sources. All data sets relied upon have been cited, where appropriate, in the manuscript and included in the reference list. A full report which outlines all methods and data sources, along with detailed results, is available on request.

\section{Authors' contributions}

LP and JS designed the study, collected data and performed data analysis. $L P, J S, P S$ and DS interpreted the findings, and drafted and revised the manuscript. All authors read and approved the final manuscript.
Consent for publication

Not applicable.

\section{Competing interests}

The authors declare that they have no competing interests.

\section{Publisher's Note}

Springer Nature remains neutral with regard to jurisdictional claims in published maps and institutional affiliations.

\section{Author details}

${ }^{1}$ Deloitte Access Economics Pty Ltd, 8 Brindabella Circuit, Canberra Airport 2609, ACT, Australia. ${ }^{2}$ Royal National Institute of Blind People, London, UK. ${ }^{3}$ Leeds Institute of Health Sciences, University of Leeds, London, UK.

Received: 20 March 2016 Accepted: 11 January 2018

Published online: 30 January 2018

\section{References}

1. Institute for Health Metrics and Evaluation (IHME). GBD Compare. Seattle, WA: IHME, University of Washington, 2015. http://vizhub.healthdata.org/gbdcompare/. Accessed 14 Jul 2016.

2. Taylor HR, Pezzullo ML, Keeffe JE. The economic impact and cost of visual impairment in Australia. Br J Ophthalmol. 2006:90:272-5.

3. World Health Organization. Universal eye health: a global action plan 20142019. Geneva, WHO Library; 2013.

4. Access Economics. Future sight loss UK (1): The economic impact of partial sight and blindness in the UK adult population. Report for Royal National Institute of Blind People (RNIB). Access Economics. Canberra. 2009.

5. Meads C, Hyde C. What is the cost of blindness? Br J Ophthalmol. 2003;87:1201-4

6. Köberlein J, Beifus K, Schaffert C, Finger RP. The economic burden of visual impairment and blindness: a systematic review. BMJ Open. 2013;3(11):e003471.

7. Cruess AF, Gordon KD, Bellan L, Mitchell S, Pezzullo ML. The cost of vision loss in Canada. 2. Results. Can J Ophthalmol. 2011;46(4):315-8.

8. Roberts CB, Hiratsuka Y, Yamada M, Pezzullo L, Yates K, Takano S, et al. Economic cost of visual impairment in Japan. Arch Ophthalmol. 2010;128(6):766-71.

9. Larg A, Moss JR, Cost-of-Illness Studies. A guide to critical evaluation. PharmacoEconomics. 2011;29(8):653-71.

10. Evans JR, Fletcher AE, Wormald RPL, Siu-Woon Ng E, Sterling S, Smeeth L, et al. Prevalence of visual impairment in people aged 75 years and older in Britain: results from the MRC trial of assessment and management of older people in the community. Br J Ophthalmol. 2002;86:795-800.

11. Evans JR, Fletcher AE, Wormald RPL. Causes of visual impairment in people aged 75 years and older in Britain: an add-on study to the MRC trial of assessment and Management of Older People in the community. $\mathrm{Br} \mathrm{J}$ Ophthalmol. 2004;88:365-70.

12. Reidy A, Minassian DC, Vafidis G, Joseph J, Farrow S, Wu J, et al. Prevalence of serious eye disease and visual impairment in a north London population: population based, cross sectional study. Br Med J. 1998;316:1643-6.

13. Evans JR, Fletcher AE, Wormald RPL. Age-related macular degeneration causing visual impairment in people 75 years or older in Britain. Ophthalmology. 2004;111:513-7.

14. Coffey M, Reidy A, Wormald R, Xian WX, Wright L, Courtney P. Prevalence of glaucoma in the west of Ireland. Br J Ophthalmol. 1993;77:17-21.

15. Congdon N, O'Colmain B, Klaver CCW, Klein R, Munoz B, Friedman DS, et al. Causes and prevalence of visual impairment among adults in the United States. Arch Ophthalmol. 2004;122:477-85.

16. Congdon N, Vingerling JR, Klein BEK, West S, Friedman DS, Kempen J, et al. Prevalence of cataract and pseudophakia/aphakia among adults in the United States. Arch Ophthalmol. 2004;122:487-94.

17. Friedman DS, O'Colmain BJ, Munoz B, Tomany MA, McCarty C, de Jong PTVM, et al. Prevalence of age-related macular degeneration in the United States. Arch Ophthalmol. 2004;122:564-72

18. Friedman DS, Wolfs RCW, O'Colmain BJ, Klein BE, Taylor HR, West S, et al. Prevalence of open angle glaucoma among adults in the United States. Arch Ophthalmol. 2004;122:532-8. 
19. Kempen JH, O'Colmain BJ, Leske C, Haffner SM, Klein R, Moss SE, et al. The prevalence of diabetic retinopathy among adults in the United States. Arch Ophthalmol. 2004;122:552-63.

20. Kempen JH, Mitchell P, Lee KE, Tielsch JM, Broman AT, Taylor HR, et al. The prevalence of refractive errors among adults in the United States, Western Europe and Australia. Arch Ophthalmol. 2004;122:495-505.

21. Das BN, Thompson JR, Patel R, Rosenthal AR. The prevalence of eye disease in Leicester: a comparison of adults of Asian and European descent. J R Soc Med. 1994:87:219-22.

22. Wormald RPL, Basauri E, Wright LA, Evans JR. The African Caribbean eye survey: risk factors for glaucoma in a sample of African Caribbean people living in London. Eye. 1994;8(3):315-20.

23. Office for National Statistics. 2010-based subnational population projections. 2012. https://www.ons.gov.uk/peoplepopulationandcommunity/population andmigration/populationprojections/bulletins/subnationalpopulation projectionsforengland/2012-03-21. Accessed 7 Apr 2014.

24. Office for National Statistics. Ethnic group by sex by age. 2013. https://www. nomisweb.co.uk/census/2011/dc2101ew. . Accessed 28 Apr 2014.

25. Greater London Authority. GLA 2013 Round Ethnic Group Population Projections. 2014; https://londondatastore-upload.s3.amazonaws.com/ Demography/document_archive/update_2013rnd_ethnic_group_results.pdf. Accessed 23 Apr 2014

26. Office for National Statistics. National Population Projections, 2012-based projections. 2013. https://www.ons.gov.uk/peoplepopulationandcommunity/ populationandmigration/populationprojections/bulletins/ nationalpopulationprojections/2013-11-06. Accessed 6 Apr 2014.

27. Department of Health. Reference Costs 2012-13. 2013. https://www.gov.uk/ government/publications/nhs-reference-costs-2012-to-2013. Accessed 16 Apr 2014.

28. Information Services Division. Scottish Health Service Costs (Costs Book). 2013. http://www.isdscotland.org/Health-Topics/Finance/Costs/File-Listings2013.asp. Accessed 16 Apr 2014.

29. Welsh Government. Health statistics Wales, 2013. 2013. http://gov.wales/ statistics-and-research/health-statistics-wales/?tab=previous\&lang=en. Accessed 18 Apr 2014.

30. Department of Health, Social Services and Public Safety, Northern Ireland. Healthcare Resource Groups. 2013. https://www.health-ni.gov.uk/ publications/acute-episode-based-activity-downloadable-data-201213. Accessed 17 Apr 2014

31. Health and Social Care Information Centre. Prescription Cost Analysis England 2013. 2014. http://digital.nhs.uk/catalogue/PUB13887. Accessed 21 Apr 2014.

32. Business Services Organisation. Prescription Cost Analysis. 2013:2014. http:// www.hscbusiness.hscni.net/services/2523.htm. Accessed 21 Apr 2014

33. Information Services Division. Prescribing Statistics - Prescription Costs Analysis. 2013. http://www.isdscotland.org/Health-Topics/Prescribing-andMedicines/Community-Dispensing/Prescription-Cost-Analysis/. Accessed 18 Apr 2014.

34. Welsh Government. Prescriptions dispensed in the community in Wales, 2003 to 2013. 2014. http://gov.wales/statistics-and-research/prescriptionsdispensed-community/?tab=previous\&lang=en. Accessed 18 Apr 2014

35. Health and Social Care Information Centre. General Ophthalmic Services, Activity Statistics: England, 2012/13. 2013. http://digital.nhs.uk/catalogue/ PUB11233. Accessed 28 Apr 2014.

36. Information Services Division. General Ophthalmic Services Statistics. 2013. http://www.isdscotland.org/Health-Topics/Eye-Care/Publications/. Accessed 28 Apr 2014.

37. Welsh Government. Eye care statistics, 2012-13. 2013. http:/gov.wales/statisticsand-research/eye-care/?tab=previous\&lang=en. Accessed 28 Apr 2014.

38. Business Services Organisation. Annual Health Service Ophthalmic Statistics in Northern Ireland. 2012/13:2013. http://www.hscbusiness.hscni.net/ services/2472.htm. Accessed 28 Apr 2014

39. Health and Social Care Information Centre. Personal Social Services: Expenditure and Unit Costs, England - 2012-13. 2013. http://digital.nhs.uk/ catalogue/PUB11644. Accessed 24 Apr 2014

40. Health and Social Care Board. Health and Social Care Expenditure Plans for Northern Ireland, 2012/13 - Supplementary analysis to the HSCB/PHA Commissioning Plan 2012/13. Northern Ireland; 2013.

41. Welsh Government. Personal social services: expenditure and activity, 200102 to 2011-12. 2013. http://gov.wales/statistics-and-research/personal-socialservices-expenditure-activity/?lang=en. Accessed 24 Apr 2014.
42. Department of Health. Department of Health Annual Report and Accounts 2012-13. 2013. https://www.gov.uk/government/publications/departmentof-health-annual-report-and-accounts-2012-to-2013. Accessed 23 Apr 2014.

43. Scottish Government. Scottish local government financial statistics 2012-13. 2014. http://www.gov.scot/Topics/Statistics/Browse/Local-GovernmentFinance/PubScottishLGFStats. Accessed 2 June 2014.

44. Department of Health, Social Services and Public Safety, Northern Ireland. Department of Health, Social Services and Public Safety - Resource Accounts for the year ended 31 March 2013. 2013. https://www.health-ni. gov.uk/publications/annual-accounts. Accessed 28 Apr 2014.

45. Department of Health. 2003-04 to 2010-11 programme budgeting data. 2011. https://www.gov.uk/government/publications/2003-04-to-2010-11programme-budgeting-data. Accessed 28 Apr 2014.

46. Office for National Statistics. Expenditure on Healthcare in the UK: 2013. https://www.ons.gov.uk/peoplepopulationandcommunity/ healthandsocialcare/healthcaresystem/articles/ expenditureonhealthcareintheuk/2015-03-26. Accessed 10 Jan 2017.

47. Williams B, Whatmough P, McGill J, Rushton L. Private funding of elective hospital treatment in England and Wales, 1997-98: national survey. Br Med J. 2000;320:904-5.

48. Health and Social Care Information Centre. Hospital Episode Statistics, Admitted Patient Care, England - 2012-13. 2013. http://digital.nhs.uk/ catalogue/PUB12566. Accessed 28 Apr 2014.

49. Scuffham PA, Legood R, Wilson ECF, Kennedy-Martin T. The incidence and cost of injurious falls associated with visual impairment in the UK. Vis Impair Res. 2002:4(1):1-14.

50. Medical Research Council. Medical Research Council Annual Report and Accounts. 2012/13:2013. https://www.mrc.ac.uk/publications/browse/annualreport-and-accounts-201213/. Accessed 24 Apr 2014

51. Department for Business, Innovation and Skills. Science, engineering and technology statistics 2013. 2013. https://www.gov.uk/government/statistics/ science-engineering-and-technology-statistics-2013. Accessed 24 Apr 2014.

52. World Health Organization. Global burden of disease and risk factors, 2006. http://www.ncbi.nlm.nih.gov/books/NBK11812/. Accessed 2 Jun 2014.

53. Lofland JH, Pizzi L, Frick KD. A review of health-related workplace productivity loss instruments. PharmacoEconomics. 2004;22(3):165-84.

54. Department for Work and Pensions. Disability Equality Indicators. 2012. http://webarchive.nationalarchives.gov.uk/20131101163230/http://odi.dwp. gov.uk/disability-statistics-and-research/disability-equality-indicators.php. Accessed 1 May 2014.

55. Office for National Statistics. Mortality statistics: deaths registered in England and Wales, 2012. 2013. https://www.ons.gov.uk/ peoplepopulationandcommunity/birthsdeathsandmarriages/deaths/ bulletins/deathsregisteredinenglandandwalesseriesdr/2013-10-22. Accessed 2 June 2014.

56. General Register Office for Scotland (GROS). Vital Events Reference Tables 2012. 2012. https://www.nrscotland.gov.uk/statistics-and-data/statistics/ statistics-by-theme/vital-events/general-publications/vital-events-referencetables/2012. Accessed 24 Apr 2014.

57. Northern Ireland Statistics and Research Agency. Deaths by ten year agebands, 1887 to 2015. 2016. https://www.nisra.gov.uk/publications/ deaths-by-ten-year-agebands-1887-2015-0. Accessed 16 Jan 2018.

58. McCarty CA, Nanjan MB, Taylor HR. Vision impairment predicts 5 year mortality. Br J Ophthalmol 2001;85(3):322-326.

59. Office for National Statistics. Annual survey of hours and earnings - resident analysis. 2013. https://www.nomisweb.co.uk/articles/793.aspx. Accessed 28 Apr 2014.

60. Organisation for Economic Cooperation and Development. OECD health data 2012. Paris 2012

61. National Institute for Health and Care Excellence. Guide to the methods of technology appraisal 2013. Process and methods guides 2013. https://www. nice.org.uk/process/pmg9/chapter/foreword. Accessed 4 Feb 2016.

62. Access Economics. The cost of partial sight and blindness in the US. Canberra: Report for USC Vision. Access Economics; 2006

63. Access Economics. The cost of partial sight and blindness in Canada. Report for Canadian National Institute for the Blind (CNIB) and Canadian Ophthalmology Society. Access Economics, Canberra. 2008.

64. Access Economics. The cost of partial sight and blindness in Japan. Report for Japan Ophthalmologists Association, National Institute of Sensory Organs, and Juntendo University WHO Collaborating Centre for the Prevention of Blindness. Access Economics. Canberra. 2008. 
65. Carers UK. Valuing carers - calculating the value of unpaid care. 2007. http:// circle.leeds.ac.uk/files/2012/09/valuing-carers.pdf. Accessed 2 Jun 2014.

66. Lafuma A, Brezin A, Lopatriello S, Hieke K, Hutchinson J, Mimaud V, et al. Evaluation of non-medical costs associated with visual impairment in four European countries - France, Italy, Germany, and the UK. PharmacoEconomics. 2006;24(2):193-205.

67. Statistics UK. Consumer price index dataset. 2014. https://www.ons.gov.uk/ economy/inflationandpriceindices/datasets/consumerpriceindices. Accessed 1 May 2014

68. Kleven HJ, Kreiner CT. The marginal cost of public funds: hours of work versus labour force participation. J Public Econ. 2006;90:1955-73.

69. Department for Work and Pensions. National statistics, November 2013. 2013. https://www.gov.uk/government/publications/benefit-expenditureand-caseload-tables-2013. Accessed 1 May 2014.

70. Department for Social Development. Benefit publications. 2013. https:// www.communities-ni.gov.uk/sites/default/files/publications/dsd/benefits_ statistics_summary_nov13.doc. Accessed 1 May 2014

71. Murray C, Lopez A. The Global Burden of Disease: a comprehensive assessment of mortality and disability from diseases, injuries and risk factors in 1990 and projected to 2020. Global burden of disease and injury series; 1. Harvard School of Public Health: Cambridge; 1996.

72. World Health Organization. The global burden of disease: 2004 update. Geneva, World Health Organization; 2004.

73. Salomon J, Vos T, Hogan D, Gagnon M, Naghavi M, Mokdad A, et al. Common values in assessing health outcomes from disease and injury: disability weights measurement study for the global burden of disease study 2010. Lancet. 2012;380:2129-43.

74. Nord E. Disability weights in the global burden of disease 2010: unclear meaning and overstatement of international agreement. Health policy 2013;111(1):99-104.

75. Taylor HR, Jonas JB, Keeffe J, Leasher J, Naidoo K, Pesudovs K, et al. Disability weights for vision disorders in global burden of disease study. Lancet. 2012;381(9860):23.

76. Chen A, Jacobsen KH, Deshmukh AA, Cantor SB. The evolution of the disability-adjusted life year (DALY). Socio Econ Plan Sci. 2015;49:10-5.

77. Mason H, Jones-Lee M, Donaldson C. Modelling The monetary value of a QALY: a new approach based on UK data. Health Econ. 2008;18(8):933-50

78. Edwards, R. Adult social care data: year ending. England. 31 March 2014: 2015. https://www.rnib.org.uk/knowledge-and-research-hub/researchreports/general-research/adult-social-care. Accessed 26 May 2015

79. Department of Health. Certificate of Vision Impairment: Explanatory Notes for Consultant Ophthalmologists and Hospital Eye Clinic Staff. 2013. https:// www.gov.uk/government/uploads/system/uploads/attachment_data/file/ 213286/CVI-Explanatory-notes-in-DH-template.pdf. Accessed 3 Jun 2016.

80. Frick KD, Kymes SM, Lee PP, Matchar DB, Pezzullo ML, Rein DB, Taylor HR. The cost of visual impairment: purposes, perspectives, and guidance. Invest Ophthalmol Vis Sci. 2010;51(4):1801-5.

81. Capita Health and Wellbeing Limited. Payment by Results Data Assurance Framework. Key findings from the 2012/13 programme. 2013. https://www. gov.uk/government/uploads/system/uploads/attachment_data/file/262027/ pbr_data_assurance_framewrk_key_find_2012-13.pdf. Accessed 15 Feb 2016.

82. Brouwer WBF, Koopmanschap MA. On the economic foundations of CEA. Ladies and gentlemen, take your positions! J Health Econ. 2000;19:439-59.

83. Heitmueller A. The chicken or the egg? Endogeneity in labour market participation of informal carers in England. J Health Econ. 2007;26:536-59.

84. Rees $P$, Wohland $P$, Norman P, Boden P. Ethnic population projections for the UK, 2001-2051. J Popul Res. 2012;29:45-89.

85. Coleman D. Projections of the Ethnic Minority Populations of the United Kingdom. Population and Development Review. 2006-2056. 2010;36(3):441-86

86. Frick KD, Foster $A$. The magnitude and cost of global blindness: an increasing problem that can be alleviated. Am J Ophthalmol. 2003;135(4):471-6.

87. Gordois A, Cutler H, Pezzullo L, Gordon K, Cruess A, Winyard S, et al. An estimation of the worldwide economic and health burden of visual impairment. Global Public Health. 2012;7(5):465-81.

88. Sassi F. Calculating QALYs, comparing QALY and DALY calculations. Health Policy Plan. 2006;21(5):402-8.

89. Mitchell P, Bressler N, Doan QV, Dolan C, Ferreira A, Osborne A, et al. Estimated cases of blindness and visual impairment from neovascular age- related macular degeneration avoided in Australia by ranibizumab treatment. PLoS One. 2014;9(6):e101072. https://doi.org/10.1371/journal. pone.0101072.

90. 4-consulting. The economic impact of free eye examinations in Scotland. Report for Association of Optometrists. Kirkcaldy, Scotland. 2012.

91. NHS Digital. People registered as blind and partially sighted. 2014. https:// data.gov.uk/dataset/registered_blind_and_partially_sighted_people. Accessed 10 Jan 2017

\section{Submit your next manuscript to BioMed Central and we will help you at every step:}

- We accept pre-submission inquiries

- Our selector tool helps you to find the most relevant journal

- We provide round the clock customer support

- Convenient online submission

- Thorough peer review

- Inclusion in PubMed and all major indexing services

- Maximum visibility for your research

Submit your manuscript at www.biomedcentral.com/submit
Biomed Central 